\title{
Silêncio e interioridade pessoal em Edith Stein
}

\author{
Silence and personal interiority in Edith Stein
}

\author{
Miguel Mahfoud*
}

Universidade Federal de Minas Gerais, Belo Horizonte, MG, Brasil

\section{Resumo}

Analisando o texto "O castelo interior" de Edith Stein, aponta-se a experiência de silêncio relacionada com cada um dos sete níveis de interioridade pessoal identificados na imagem do castelo. Comentando em termos de antropologia filosófica o texto sobre experiência mística de Teresa D'Ávila, Stein abre caminho para a identificação de diversas modalidades de silêncio: silêncio baseado na dispersão da pessoa na vivência das circunstâncias externas, silêncio ligado à experiência de si nas vivências das circunstâncias, silêncio associado a respostas a apelos identificados na própria experiência, silêncio vivido na busca da própria interioridade pessoal, silêncio diante do acontecimento da própria pessoa e do mundo com seu mistério, silêncio nas experiências de lucidez, silêncio definitivo e silêncio na vivência do núcleo da pessoa. As diversas modalidades de silêncio são apresentadas na sua conexão com cada grau da estrutura graduada do ente. Apontam-se implicações para uma ciência da experiência propriamente humana.

Palavras-chave: Edith Stein. Fenomenologia. Silêncio interior. 


\section{Abstract}

Through the analysis of Edith Stein's "The interior castle", the present study aims at the experience of silence related with each of the seven levels of personal interiority identified in the image of the castle. Commenting in terms of philosophical anthropology and based on Teresa of Ávila's text on mystical experience, Stein opens the way for the identification of various modalities of silence: silence based on the dispersal of the person in the lived experience of external circumstances, silence related to the experience of the self in the lived experiences of the circumstances, silence related to answers to appeals identified in the experience itself, silence lived in the search of one's own personal interiority, silence in front of the event of the person itself and of the world with its mystery, silence in the experiences of lucidity, definitive silence and silence in experiencing the person's core. The various modalities of silence are presented in their connection with each degree of the graded structure of being. This study points at implications for a properly human science of experience.

Keywords: Edith Stein. Phenomenology. Interior silence.

\section{Introdução}

As contribuições de Edith Stein vêm sendo enfatizadas, nos últimos anos, em todo o mundo, pela precisa relação entre os âmbitos da religião e da filosofia (ALES BELLO, 2009; MACINTYRE, 2006; MAHFOUD e SAVIAN FILHO, 2017; FACULDADE DEHONIANA, 2016) e particularmente quanto ao contínuo processo de formação da pessoa tem-se dado destaque à sua complexidade, que leva a considerar tanto a relação indivíduo-comunidade-sociedade-Estado quanto o acesso à interioridade pessoal nos processos de subjetivação (SANTOS e FARIAS, 2014; SAVIAN FILHO, 2014; SBERGA, 2015; KUSANO, 2014; MAHFOUD, 2013). O problema do acesso à interioridade pessoal com as diversas estratificações e suas correspondentes modalidades de elaboração da experiência do mundo vivido pode ser ricamente examinado a partir do ensaio steiniano "Castelo interior" (STEIN, 1999a). Ali, a autora dá uma contribuição bastante original ao evidenciar que a experiência mística revela uma estrutura pessoal humana, válida não 
apenas para quem chegou a vivenciar aquele tipo de experiência religiosa mas possível para todos os seres humanos. De fato, aquela obra steniana é um comentário - em termos de antropologia filosófica contemporânea - ao livro “Castelo interior ou moradas" de Teresa D'Ávila (2008), originalmente datado do séc. XVI, que descreve um percurso de aprofundamento da experiência mística.

Ao "buscar na constituição graduada do ente as características específicas do ser humano" (STEIN, 1999a, p. 117), Stein visa naquele texto a apreensão da estrutura humana com seus diversos graus de profundidade como convite a darmo-nos conta dela, além de problematizar caminhos possíveis para cada ser humano adentrar a própria vivência a fim de chegar a "estar em casa consigo mesmo" (p. 146).

$\mathrm{O}$ presente artigo quer tematizar a vivência de silêncio presente nos diversos níveis de experiência, assim como apontados teoricamente pela própria Edith Stein e de algum modo também identificado por ela em suas observações da vida cotidiana registradas em seus escritos autobiográficos - "Vida de uma família judia" (STEIN, 2002c), "Como cheguei ao Carmelo" (STEIN, 2002b) - e em suas cartas (STEIN, 2002a).

Embora no ambiente religioso seja frequente o uso da expressão "caminho do silêncio interior" ao se referir às contribuições de Stein, no âmbito acadêmico ainda não se deu atenção ao tema do silêncio no contato com o mundo-da-vida e na experiência da interioridade pessoal assim como a autora o sistematizou. Podemos citar como significativa exceção a tese sobre hermenêutica do silêncio contemplativo de Michele Therese Kueter Petersen (2011), que, baseada em Ricoeur, chega a abordar diretamente a elaboração de Stein. Quanto a contribuições significativas ao tema do silêncio pessoal em geral, no âmbito acadêmico, podemos citar o clássico trabalho de Rudolf Allers (1946) “On darkness, silence and the nought" e o artigo do brasileiro Walter Andrade Parreira (2014) sobre fenomenologia, espiritualidade, consciência e meditação.

Edith Stein abordou diretamente o tema do silêncio no anexo sem título posteriormente intitulado "Caminhos para o silêncio interior"1

Na verdade trata-se de um anexo originalmente sem título, identificado como "St. Lioben, 12.1.1932" conservado pela própria Edith Stein junto do manuscrito do seu texto "As bases da formação feminina". Nas Obras Completas em espanhol 
(STEIN, 2007) e no texto “Teologia mística de Pseudo-Dionísio" (STEIN, 2004), além de comentar sobre a experiência de quietude ao tratar do tema do núcleo da pessoa em "A estrutura da pessoa humana" (STEIN, 2013) e em "A estrutura ôntica da pessoa e o problema de seu conhecimento" (STEIN, 1999b). Mas é no seu texto "O castelo interior" (STEIN, 1999a) que a autora relaciona o tema do silêncio diretamente aos diversos níveis da elaboração da experiência, inclusive chegando a tematizar o problema da ciência que dê conta da complexidade da experiência pessoal. Por isso, o presente artigo toma em análise sobretudo esse último texto steiniano referido.

\section{Silêncio e exterioridades}

O silêncio é facilmente identificado como fator importante nos processos de tomada de consciência por parte do sujeito da experiência quanto ao que lhe acontece, quanto ao que o mundo é para si, quanto a presença de outros, e quanto a própria presença para os demais; no silêncio pode-se dar-se conta do movimento que a própria pessoa está realizando e do que o real está promovendo em si.

Já no início de "O castelo interior" Stein (1999a) identifica uma primeira faixa de experiência na qual nos ocupamos do mundo, através de atividades, ou até mesmo nos ocupamos de nós mesmos mas em termos de objeto: como se estivéssemos fora de nós mesmos. Nessa esfera de experiência, estamos ligados ao mundo mas sem a nossa própria presença. Retomando a imagem proposta por Teresa D'Ávila da pessoa como um castelo, a vivência de si e do mundo apoiada na exterioridade corresponde, também para Stein, a girar junto das muralhas do castelo sem adentrá-lo, ou seja, sem adentrar nossa própria pessoa e nossa própria subjetividade. Ressoando o texto teresiano, Stein aponta que as pessoas ficam "habituadas a ocupar-se com coisas exteriores a ponto de lhes parecer impossível poder entrar em si mesmas" (p. 119),

está publicado no volume IV às páginas 210-213 e em português, no livro A mulher: sua missão segundo a natureza e a graça (Edusc, 1999) às páginas 151-154.

Rev. Filos., Aurora, Curitiba, v. 29, n. 48, p. 840-864, set./dez. 2017 
tendendo a permanecerem fora de si mesmas, ainda que seja "uma situação patológica que uma pessoa não conheça a própria casa" (p. 119) ou que não esteja em casa consigo mesma.

Problematizando, Stein se interroga sobre "o que pode mover o ser humano a entrar, uma vez que, voltado inteiramente para o que é exterior, ele não percebe [em si] os convites" à interioridade (1999a, p. 120). O que viria a possibilitar - a quem lida com tudo como objeto que se voltasse à própria subjetividade?

Stein (1999a) assinala que Teresa D'Ávila não dá resposta à questão, mas deduz que para esta a resposta estaria ligada ao habitus²: no contexto religioso, seriam determinantes os convites à oração e meditação.

Trata-se de uma pergunta importante para nós contemporâneos por não sermos formados para ter habitus de atenção para conosco mesmos; coletivamente, não somos convidados à interioridade. Fica aberta, então, a pergunta, que permanece um problema interessante: qual é o nível da experiência que contém um chamado à interioridade e que tipo de resposta da pessoa não se refere a adestramento (modulado desde fora), mas é posicionamento pessoal que a estruture, que a forme (no sentido preciso do termo) (MAHFOUD, 2013; SBERGA, 2015; STEIN, 1999c, 2013).

Então, podemos tomar o silêncio como significativo tema contemporâneo, chamando em causa a atenção para conosco mesmos, o reconhecimento de si e do mundo em termos efetivamente pessoais, ainda que permaneça como desafio.

Examinando os escritos autobiográficos e as cartas de Edith Stein (2002a, 2002b, 2002c), pode-se notar que o tema do silêncio aparece de formas variadas, acompanhando o percurso de vida da autora: vai se tornando menos exterior, menos referido ao ambiente, e mais associado

2 Habitus: "É uma disposição, uma capacidade da natureza humana, a qual se enraíza em sua natureza específica e individual, finalizada pelo agir. É como um intermediário entre o dado ontológico e dinâmico da natureza e seu acabamento humano, a exemplo do processo de crescimento que conduz o recém nascido à idade adulta, ao homem 'perfeito', terminado (perficere, em latim). Assim, o habitus é uma qualidade, e a primeira, nas categorias predicamentais de Aristóteles. É, num homem completo, a disposição ao melhor. [...] Só existe habitus nas disposições naturais do homem que não sendo regradas pelo instinto e por outros determinismos, deixam abertura para descobrir a boa maneira de um agir adaptado ao concreto de um ato singular, e em fidelidade à natureza humana no que ela tem de específico. Nos termos de psicologia contemporânea, 0 habitus é um dinamismo estruturado e estruturante da pessoa" (MASSIMI, 2013, p. 119). 
à consciência do que acontece em sua própria pessoa. O próprio relato de Stein sobre suas experiências de vida pode nos auxiliar na identificação das diversas modalidades de silêncio das quais trata em seus textos filosóficos.

Sobre o silêncio vinculado à experiência ao ocupar-se da exterioridade, ainda sem adentrar a vivência íntima, podemos identificar diversas passagens, como as que seguem. Stein relata o silêncio do irmão que vai ficando cada vez mais tímido e retraído (cf. STEIN, 2002c, cap. I.3); ou do silêncio da mãe que se contém para não explodir com o irmão ou com ela mesma (cf. STEIN, 2002c, cap. II.1.1). O silêncio dela mesma: vai se tornando cada vez mais silenciosa devido às chacotas dos irmãos maiores, a ponto de não querer participar do mundo dos grandes, retirando-se dos acontecimentos do grupo familiar (cf. STEIN, 2002c, cap. II.1.2).

Há também o silêncio do vazio: Stein relata que, tendo feito o exame de bacharelado - algo que desejava muito - , no dia seguinte a alegria já não estava presente: sem que o desejasse, a experiência de algum modo se esvaziara, deixando-a em silêncio (cf. STEIN, 2002c, cap. II.3.5). E ainda o silêncio de quem é calado pela dialética do professor (cf. STEIN, 2002c. cap. II.4.1), o silêncio do amigo que fica quieto enquanto ouve uma repreensão (cf. STEIN, 2002c, cap. II.4.3), ou o silêncio de quem omite parte desagradável de uma história narrada (cf. STEIN, 2002c, cap. II.6.1).

Relativo à exterioridade, há ainda o silêncio que revela a postura de outra pessoa, como uma "silenciosa amabilidade" (STEIN, 2002c, cap. II.6.2, p. 365), um "silêncio referencial" de alguém (STEIN, 2002c, cap. II.6.2, p. 360) e silêncio de pessoa orgulhosa (cf. STEIN, 2002c, cap. II.7.3).

E o silêncio associado a acontecimentos do ambiente relacional, como ficar sem graça ao presenciar cenas desagradáveis (cf. STEIN, 2002c, cap. II.7.1), e o de quem deixa algo sempre para depois, a ponto de o silêncio se tornar uma tortura (cf. STEIN, 2002a, carta 90); ou o silêncio de quem se afasta do convívio numa festa, o silêncio temeroso da jovem ao ser acompanhada por um rapaz ao voltar para casa à noite (cf. STEIN, 2002c, cap. II.7.1) e o de quem "guarda silêncio" como segredo (cf. STEIN, 2002b, p. 505). 
E há várias passagens onde o silêncio se configura como um campo aberto a ser interpretado, como que em busca de um porquê. Por exemplo, o silêncio de Husserl poderia significar desaprovação ou apenas mau-humor e os discípulos precisavam tentar discernir (cf. STEIN, 2002a, carta 238). Nas cartas de Edith Stein a seu colega Roman Ingarden, por exemplo, há diversas tentativas de explicar o fato de não ter escrito antes, ou de dar sentido à demora das respostas, entrando em conjecturas, a ponto de a comunicação entre eles ficar confusa diante das explicações insatisfatórias, até chegarem a desistir de se comunicar por falta de um solo em comum, quando o silêncio gera impossibilidade de comunicação (Cf., por exemplo, STEIN, 2002a, carta 38; carta 118). Há também o silêncio da plateia ao final de uma palestra de Stein, revelando a ela que não haviam gostado (Cf. STEIN, 2002a, carta 246), ou o silêncio que trai o autor de um gesto que desejaria permanecer incógnito (cf. STEIN, 2002a, carta 441).

São exemplos que podem nos oferecer clareza sobre as características das experiências de silêncio no campo marcado pela exterioridade. Ali podemos nos ocupar de tudo, inclusive do próprio silêncio, mas de algum modo permanece campo minado: relações afetadas por significados não claros, o empenho para adentrar a própria experiência permanece confuso. São exemplos de tentativas de lidarmos com a própria experiência e com a do outro sem a força própria de quem "está em casa", pulverizados em meio às diversas experiências. Exemplos que evidenciam a necessidade de superar esse nível de experiência para poder dar conta do próprio fluxo de vivências.

\section{Silêncio na percepção de si ligada à exterioridade}

Stein aponta uma primeira instância em que se dá consciência de si, consciência de um eu, ainda associada a elementos exteriores à pessoa mesma. Seria como adentrar a morada mais externa do castelo interior, a que recebe luz da exterioridade e é afetada pelos rumores de fora (STEIN, 1999a). Assim, o tema do eu começa a interessar a pessoa mas é como se ela não tivesse elementos do próprio eu para sua 
elaboração; e o silêncio é vivido a partir do ambiente, ao favorecer a experiência de aquietar-se, por exemplo, ou como adesão ao silêncio vivido por outros. Nesse nível de experiência, a pessoa "não pode considerar si mesma sem pensar ao mesmo tempo nas coisas que a amarram" (STEIN, 1999a, p. 120), sem as coisas das quais ela depende para ter percepção de si.

Interessante notar que a vinculação da consciência de si ao contexto por um lado ressalta a exterioridade e por outro aponta as sensações como possibilidade de iniciar a tematização sobre o eu. De fato, o adolescente percebe a si mesmo no embate interpessoal, abrindo a problematização sobre si mesmo e sobre o mundo, mas é evidentemente ainda o primeiro degrau em direção a uma autonomia muito maior.

\section{Silêncio e resposta a apelos reconhecidos na própria experiência}

No nível de experiência correspondente à segunda morada do castelo interior, o mundo-da-vida traz para a pessoa certos apelos ao entrar em contato com as coisas, ao agir e viver desejos (STEIN, 1999a; cf. STEIN, 2013, cap. VI.II.4). Uma jovem percebida em sua "silenciosa amabilidade" suscita uma reação segundo a qual o sujeito quer tratá-la bem, pela qual ele percebe a si mesmo por meio da reação (como citado anteriormente) e, além disso, pode advertir um "apelo" na própria experiência que se refira a um anseio não mais da ordem da reação mas da vontade e da tomada de posição livre. Responder a partir da percepção detém o sujeito atado ao exterior, mas a resposta pode se basear no que o elemento exterior solicita em termos de interioridade do sujeito, suscitando tomadas de posição livres.

Por que aí entra em questão o eu? Porque o eu pode se colocar no nível de experiência da reação ou na tomada de posição: a pessoa pode aceitar a provocação advinda do apelo advertido na própria experiência (onde há reconhecimento de valor, de bem, ainda que fosse fluido e impreciso) ou permanecer atenta à exterioridade (às coisas, ao outro e a si mesma como objeto). A resposta pessoal ao apelo advertido não se 
refere mais ao mundo como objeto mas é atividade do eu que se volta ao mundo reconhecido em seu valor.

No dizer de Stein (1999a, p. 146),

o eu aparece como um ponto móvel [...]; seja onde for que ele se detenha e tome posição, lá acende-se a luz da consciência que ilumina um certo âmbito: seja no íntimo da alma, seja no mundo objetivo ao qual esse eu se dirige. Não obstante sua mobilidade, o eu permanece sempre ligado àquele imóvel ponto central da alma, no qual se encontra verdadeiramente em casa. Por esse centro ele é contínua e precisamente solicitado [...] a tomar decisões últimas, aquelas para as quais o ser humano é chamado como pessoa livre.

Em sua autobiografia, Stein relata momentos de conversas noturnas com suas irmãs e o gosto de trocar de quarto e de parceira de diálogo, por ser a noite um momento propício para maior confidência (cf. STEIN, 2002c, cap. II.3.2). De fato, o ambiente favorece uma vivência e, ao mesmo tempo, abre-se o campo da escolha do nível de experiência em que o eu se coloca, afirmando o valor apreendido ou permanecendo distraído de si mesmo. Diante de uma estrutura ambiental estabelecida - relacionamentos na organização espaço-temporal, por exemplo - há identificação de apelos, de convites a uma abertura para o outro e possibilidade de colocar no mundo-da-vida algo marcado pela interioridade pessoal.

Stein relata algo do gênero também quando se refere ao relacionamento entre os membros do Círculo de Gotinga (cf. STEIN, 2002a, carta 89): em determinado ambiente adverte-se em si, mais fortemente, um apelo a um nível mais profundo e livre de relação, podendo-se, então, dar direção, escolher relacionamentos, aproveitar ocasiões ou deixá-las passar: mobilidades do eu a partir do reconhecimento de possibilidades e de valor.

Em outra passagem Stein (cf. 2002c, cap. II.4.3) relata um passeio junto a um amigo ao saírem de uma festa: caminhavam na noite sob o clarão da lua, em silêncio, observando a cidade e numa percepção poética o trem passava como uma serpente luminosa; e o amigo lhe diz que aquele era o momento mais bonito da festa. $\mathrm{O}$ contexto abre 
possibilidades, e apelos a adentrar em níveis mais complexos de experiências são advertidos pelos sujeitos; e o reconhecimento de valor pode ser afirmado de modo pessoal e integrado à vivência. Os apelos são advertidos e vividos no silêncio interior. Ao mesmo tempo, os apelos convidam ao silêncio.

\section{Silêncio e busca da interioridade pessoal}

Num terceiro nível da "constituição graduada do ente", a pessoa busca a interioridade que, de alguma maneira, já foi reconhecida como valor (STEIN, 1999a).

Retomando passagens indicadas acima, a partir de experiências de confiança entre irmãs ou de liberdade entre membros do mesmo grupo de pesquisa, por exemplo, a pessoa pode passar a buscar aquele tipo de experiência pessoal: se organiza para isso, faz escolhas, se locomove etc. Interessante notar, porém, que Stein (1999a) - ressoando Teresa D'Ávila (2008) - mostra que, embora seja movimento de um eu, com vontade afirmada, a iniciativa não é capaz de gerar o silêncio: esse pode ser reconhecido, apreciado e até buscado, mas não pode ser gerado pela pessoa mesma. A busca pela interioridade acaba gerando certa inquietação - de pensamentos e sensações.

É fato que ao vivenciar o mundo-da-vida o sujeito adverte um apelo em si, reconhece valor, pode dar uma resposta, atuando seu eu no âmbito da vontade e da liberdade. E Stein aponta também que tudo isso ainda não basta ao sujeito da experiência, porque no exercício da vontade e na atividade do eu ainda pode-se gerar ansiedade, não se chega ainda a "estar em casa consigo mesmo". Dar-se conta de limites leva a buscar mais, e mais intensamente; identificar valor, advertir a própria interioridade e seu silêncio são momentos de "consolação" (STEIN, 1999a, p. 121) diante dos limites em que constantemente se está. 


\section{Silêncio diante do acontecimento}

A quietude é própria somente do quarto nível de interioridade pessoal, a quarta morada do castelo interior (STEIN, 1999a). Nesse grau de interioridade pessoal tem-se condições de dar-se conta do próprio processo de elaboração das vivências a ponto de reconhecer a diferença entre um valor intensamente e ansiosamente buscado e a experiência de aquietar-se ao encontrar algo grandioso e correspondente aos anseios.

O contexto cultural contemporâneo que tem tomado a subjetividade como pura narrativa ou que tem concebido a constituição do eu pelos próprios projetos ou por certas tendências não chega a tocar no âmbito da surpresa frente a própria vida que permite a experiência da quietude e dá condições para lidar de modo pessoal com projetos, tendências, desejos, vontade (não como exterioridade ou algo a ser ainda buscado mas como acontecimento).

O reconhecimento de um valor ou de um significado de certa pessoa para mim, não é apenas algo do exterior que me afeta devido às características do objeto, mas principalmente aquele reconhecimento faz com que eu tome o mundo a meu modo, com tomada de consciência de mim mesmo além das representações já estabelecidas. $\mathrm{O}$ eu se constitui não pelo próprio voluntarismo, mas pela consciência de si e pela experiência de liberdade pessoal que emerge ao aplicar a vontade no mundo da vida, indo além dos próprios projetos.

Assim, a pessoa pode chegar a afirmar que já nem interessam muito os elementos de consolação e provação a que nos referimos anteriormente (avanços ao buscar alcançar certos valores ou consciência de passos ainda a serem dados): o importante é o acontecimento pessoal de estar afetada por algo de valor.

No contexto cultural contemporâneo, habituados a atentar à exterioridade, ao advertir algum convite para a interioridade facilmente nos voltamos à própria vivência como fechamento sobre si mesmos, de modo que continuamos fora da vida acontecendo. No entanto, como seres humanos, temos condições de viver o impacto que recebemos do mundo reconhecendo um processo significativo acontecendo, e podemos decidir sobre essa vivência. Assim, Stein (1999a) aponta que na 
experiência de quietude afirmamos nossa própria pessoa sem esforço pessoal algum, afirmamos o outro sem nenhum projeto: um livre movimento do eu.

Atualizando uma imagem de Teresa D'Ávila, Stein (1999a) comenta que no nível anterior é como se a pessoa fosse, com um pote, buscar água que vem de longe e é contida fazendo barulho. Enquanto que no nível de experiência atual é como se ela fosse pegar a água diretamente da fonte, que está imediatamente ali, inundando o pote-pessoa silenciosamente e ampliando as experiências. Stein fala mesmo num pote elástico: as experiências de reconhecimento de valor vão modificando a estrutura da pessoa. Em certo sentido aumenta a tensão, mas sem aquele esforço, agitação e rumor interior.

Nesse nível de experiência dá-se o silêncio interior dentro do acontecimento da vida, do acontecimento para mim, do reconhecimento da vida acontecendo.

Assim, nem interessa mais tanto a consolação, mas o acontecimento; já nem interessa muito identificar o nível em que eu estou: paradoxalmente, meu movimento está mais livre. Em certo sentido, estou mais esquecido de mim mesmo; ao mesmo tempo, meu eu está mais presente. Num certo sentido, eu estou mais passivo (por estar mais atento ao impacto que eu recebo do que ao que faço); por outro lado, estou mais ativo, pois o meu eu está mais em ação, toma posição, reconhece o valor (STEIN, 1999a).

Em uma passagem da autobiografia, Edith Stein usa a expressão "silenciosa alegria" ao reconhecer a experiência de realização que sua irmã fazia ao trabalhar (STEIN, 2002c, p. 197); em outra, comentando sobre uma irmã mais velha, escreve: “Especialmente por sua evolução religiosa, ela se abriu a um mundo que lhe permite renunciar a todas as satisfações externas e a perseverar silenciosamente em seu lugar" (p. 185). Significa que ela não estava em busca da conquista de seu lugar, mas que a experiência de reconhecimento de algo grande acontecendo possibilita "perseverar silenciosamente em seu lugar", no próprio eu, no lugar do próprio eu no mundo.

Aquela quietude envolve inclusive aquietar a imaginação e o intelecto, segundo Teresa D'Ávila (2008) e Edith Stein (1999a): nessa 
experiência o que importa não é o que se imagina sobre si, sobre o outro, sobre Deus, não se trata de uma construção de imagens, nem de esforço de se adequar a algo imaginado por si mesmo ou por outros; e o intelecto entra não na articulação de elementos mas no reconhecimento de um valor, da própria liberdade, da realização que a experiência de quietude comporta.

Em certo sentido há passividade e em outro, refinamento da atividade do eu e do intelecto. A atividade do intelecto está mais no reconhecimento do processo, na contemplação, do que na explicação do fenômeno. É como se a explicação ficasse desfocada, por não ser tão necessária. Por que você ama aquela pessoa? Toda explicação é insatisfatória e incompleta, mas o reconhecimento de algo significativo, de que há muitas consequências importantes e de que naquela experiência você é mais si mesmo, tudo isso é reconhecimento intelectual.

Edith Stein (2002b, p. 500) descreve a ocasião em que um professor-administrador lhe comunica que não mais poderia lecionar devido às restrições das leis nazistas contra os judeus, o que acarretaria em um novo passo:

No próximo outono a situação ficaria mais clara, o instituto poderia passar a ficar a cargo da Igreja e então não haveria oposição a minha colaboração. Recebi o comunicado muito serenamente. Esta esperança consoladora pouco me importava. "Se não dá, então já não resta para mim possibilidade alguma na Alemanha". $\mathrm{O}$ administrador expressou admiração por minha visão tão clara apesar de viver tão abstraída e de me preocupar tão pouco com as coisas deste mundo.

Podemos tomá-la como exemplo de experiência de quietude: dentro da situação inquietante e marcada por limites, certo distanciamento das circunstâncias, desinteresse por consolações, reconhecimento de valor, intelecto voltado a reconhecer possibilidades abertas mais do que imaginar o futuro incerto. Não se refere a insensibilidade ou infundado otimismo, mas um processo pessoal que transpassa a preocupação que a circunstância traz. A preocupação que descentra - que leva a pessoa a ficar insegura diante das possibilidades abertas - está no nível das moradas mais externas do castelo interior. Do ponto de 
vista mais interno, a inteligência transpassa a circunstância e a espera - que faz parte dessa quietude - abre caminho para o próximo nível da interioridade (a morada da união).

\section{Silêncio e lucidez}

No momento descrito acima, certamente entra em jogo a decisão: ficar ligada ao mistério da situação e da sua própria vida, mais do que ao problema que se apresentava. Trata-se do movimento do eu, momento de liberdade, de escolha, e sobretudo de adesão ao que se manifesta. Trata-se de reconhecimento, não de imaginação; reconhecimento esse ancorado na experiência de Deus, do mistério que a própria vida é, de modo que ela pode pensar sua pessoa, como ligada a algo que está além do próprio eu.

É como se meu olhar estivesse se perdendo na pessoa amada, está todo no outro, com a certeza de que algo grande está acontecendo (sem se preocupar com o que vou fazer com isso).

Nesse nível de interioridade pessoal, não há mais separação entre mim e meu projeto, entre mim e o que eu gostaria de ser, entre mim e os problemas que incomodam. Há um reconhecimento de um fundamento da vida acontecendo a dar estabilidade impossível pelos próprios esforços.

O que está em jogo é a unidade da pessoa com algo-outro, fonte do nosso eu. Surpresos com a própria existência, maravilhados com a vida jorrando. Atenção ao acontecimento de vida, mais do que às minhas próprias características: minha vida, com seus limites e possibilidades, é uma surpresa. Dá-se um maravilhamento pelo mistério de um acontecer que eu não seria capaz de fazer mas ele está se dando. $\mathrm{O}$ foco já não é o próprio eu, mas o acontecimento: Deus está gerando a vida; eu não poderia fazer a mim mesmo mas existo; poderia não estar vivo mas estou...

Trata-se uma atenção que vai além de mim, se volta a um mistério da vida acontecendo, de modo que as inquietações se aplacam e dá-se a unidade com o não eu que é a possibilidade do eu. 
Tais experiências são momentos de lucidez. Como tal, são passageiras e também permanecem como referência. Por exemplo, todo casal em algum momento se pergunta "Por que mesmo entramos nessa?", o que abre a possibilidade de retomar uma experiência de abertura vivida na origem do relacionamento, que os caracteriza mesmo que em muitas ocasiões a abertura possa vir a ser substituída por negociações de regras e acordos sem conexão alguma com a abertura original. Essas experiências de abertura e unidade são como flashes de luz, nesse sentido.

A quinta morada do castelo interior é caracterizada pela união de breve duração mas que instaura uma vivência da qual não se esquece mais. Stein (1999a) e Teresa D'Ávila (2008) a comentam em termos de experiência mística, caracterizada por uma certeza sobre a qual nem se consegue falar adequadamente, não se dá conta de justificar a certeza ou demonstrar seu conteúdo, mas não se esquece nunca mais dela. Dá-se uma ativação da vontade, do intelecto e da memória (justamente as chamadas potências da alma).

Naquela ativação da consciência de meu eu, posso perder a clareza própria daquele momento - porque a ativação é breve - e passo a me dar ao trabalho de retomar como aconteceu. Tenho saudade daquela experiência, sei que preciso dela. E sei de que quietude se trata, sei a que silêncio se refere, bem como sei que tipo de realização a experiência contém. Essas características são fundamentais por abrirem um campo de possibilidades, por continuarem a abrir para uma experiência real, que permite o movimento de busca - não mais a busca da efetivação do projeto ou do valor a ser atingido, mas a busca de uma experiência da qual se permanece sempre à espera. Sempre à espera, pois pode acontecer de perdê-la mas posso esperar com a certeza de quem sabe de que se trata.

"Vagam em torno do castelo e é tão difícil para eles superar esse hábito" (STEIN, 1999a, p. 123): faz-se uma experiência de adentrar a interioridade, mas deixar de vagar na exterioridade é um trabalho; no entanto, na quinta morada do castelo interior não é mais um trabalho do meu esforço, mas trabalho do meu reconhecimento, reconhecimento do acontecimento, reconhecimento do divino, é o reconhecimento de uma união que me constitui: somos "arrastados para o alto, o que 
economiza muito trabalho, mas cuja preparação e tradução em ato trazem fortes solicitações à vontade" (p. 128).

A experiência de breve união é profundamente íntima. Há a atividade de reconhecimento, mas nem se consegue falar adequadamente do que foi vivido. Aliás, busca-se não falar para não se perder o silêncio de que a experiência é feita. De fato, em uma carta, Stein chega a comentar: "O mais importante eu não queria falar" (STEIN, 2002a, carta 370, p. 1038), e ainda “O melhor desses dias, repletos de graça, não se pode dizer e muito menos escrever" (STEIN, 2002a, carta 211, p. 854). Trata-se do silêncio no íntimo de si como dádiva e tomado pela vontade empenhada: a vontade de adentrar mais no silêncio, de não perdê-lo. Vontade também de não banalizar, de não permitir que seja a linguagem habitual (que não dá conta do acontecimento) a dar os contornos da vivência: manter silêncio é de algum modo empenho da vontade em defender a própria experiência: "o mais importante eu não quero falar".

Esse cuidado com a própria experiência chama para o silêncio, que no quinto nível da interioridade não é silêncio de alienação, não leva a interrupção do processo; pelo contrário, é empenho no cuidado do que se sabe frágil: sabe-se ser breve, sabe-se da necessidade de um trabalho para sua recuperação. Tal cuidado é movimento do eu na interioridade pessoal.

A defesa da própria interioridade se dá também pelo silêncio e quer evitar que a incompreensão entre as pessoas gere distanciamentos. Tal experiência de interioridade, num certo sentido, separa a pessoa dos demais, mas a experiência de união gera um silêncio que passa a compor a relação com o outro. Aquele silêncio coloca algo no mundo. De fato, no dizer da própria Stein (1999a, carta 399, p. 1068): “Os serviços básicos do amor agora devem ser efetuados através de um caminho silencioso. Creio, inclusive, que assim posso ajudá-los mais do que com palavras".

Em uma carta, Stein comenta que no silêncio ela conserva vivas as experiências e pelo silêncio também participa da construção do mundo-da-vida:

Como você pode notar, o santuário de São Bento na Silésia não se soltou de mim desde que estive lá. Assim como Beuron e Neuburg, agora ele 
está inscrito, indelével, no meu coração, e de longe procuro trabalhar completamente em silêncio em sua construção, tanto quanto posso" (STEIN, 1999a, carta 198, p. 837).

No significado da união com Deus, o silêncio constrói o mundoda-vida, com empenho.

Os psicólogos clínicos vivenciam o silêncio como construtivo da relação interpessoal: o silêncio é espera do significado e do valor que está por emergir no vívido presente; assim, a espera silenciosa compõe a situação, criando um clima perceptível mesmo por um observador externo. E mesmo na cultura popular brasileira, a experiência de silêncio profundamente enraizada na interioridade pessoal modula sensibilidades e relacionamentos: uma senhora de cem anos num distrito rural mineiro certa vez ficara alguns instantes em silêncio e depois, levantando os olhos cheios de brilho, disse "Como é doce pronunciar o nome de Jesus" fazendo com que os presentes ficassem chocados com aquele silêncio e também em silêncio permanecessem (MAHFOUD, 2014).

Naquele nível de interioridade pessoal, a relação vivida intimamente cria um clima entre nós, convidando todos a um novo olhar. A explicação de que habitualmente precisamos para chegar a conceber o Divino presente (nas coisas, pessoas e acontecimentos) não tem força de apelo como a daquele olhar e daquele silêncio. O próprio fato de a pessoa estar voltada à sua experiência na profunda interioridade é um apelo.

Há uma passagem significativa nesse sentido, relatada por Stein em sua autobiografia (cf. STEIN, 2002c, cap. II.9.2): antes de sua conversão ao catolicismo, enquanto visitava uma catedral, entra uma pessoa simples com um cesto de trabalho e se ajoelha em silêncio; ela fica muito impactada com aquela experiência de pessoalidade num relacionamento íntimo acontecendo diante de seus olhos. O silêncio daquela pessoa, que nem sabia estava sendo observada, coloca algo no mundo, que se torna um apelo para Edith se colocar no nível de reconhecimento de valor, nunca mais esquecido: "uma pessoa comum, em meio a seus trabalhos diários, na igreja vazia, chegava para um diálogo confidencial. Isso nunca pude esquecer" (p. 480-481).

Nas experiências da quinta morada do castelo interior, uma união breve instaura um patamar novo de consciência; posso até não 
permanecer nele no momento seguinte, mas eu nunca mais esqueço. É uma possibilidade para todos nós. Podemos esperar voltar à experiência já vivida e esperar que ela cresça. Podemos fazer esforço pra isso, nos dispormos a isso (ficar mais em silêncio, visitar certas pessoas etc.), podemos nos mover, mas não como quem conquista com as próprias forças; podemos nos mover como quem ama, como alguém que movimenta seu eu num reconhecimento de união.

\section{Silêncio definitivo}

A sexta morada do castelo interior é o campo da experiência onde a união é selada, marcada para sempre, torna-se estável.

Na cultura contemporânea tenderíamos a conceber esse nível de experiência como tranquilidade, como não ser afetado por contextos e circunstâncias. No entanto, a descrição deste nível de interioridade pessoal traz à tona, paradoxalmente, sofrimentos enormes (STEIN, 1999a, TERESA D'ÁVILA, 2008). A experiência é agora marcada por deixar a imaginação e se ligar no acontecimento de amor; e por que o sofrimento? Porque em uma experiência de horizonte tão amplo, de tamanha profundidade de consciência de si mesmo unida à consciência do mistério da vida acontecendo, a pessoa não fica sossegada em relacionamento algum, em instituição nenhuma, nem mesmo consigo mesma e com os próprios projetos, uma vez que o apelo nos leva a algo muito fora do imaginado para si; os tropeços que tal experiência traz no quotidiano estão fora de nossos planejamentos. Mas ao mesmo tempo se aprofunda a experiência descrita anteriormente, no sentido de que a experiência do reconhecimento desfoca o problema do sofrimento: é o que acontece na capacidade de sofrer em uma experiência de amor (experiência das mães ou de quem trabalha por um ideal). Não é que o sofrimento não exista; ele toma significado dentro de um horizonte estável, de vinculação da própria pessoa ao mistério. E assim, os sofrimentos, "quanto mais em silêncio, menos são sentidos" (STEIN, 2002a, carta 226, p. 869). 
Na mesma carta, Stein diz dar-se conta de que muitas correntes - que a detinham ligadas às coisas - foram rompidas, admira-se com a experiência de liberdade que está vivendo; e vislumbra que grandioso será quando todas as correntes forem rompidas: ela olha para o fim como o completar-se de uma experiência que já faz: esperança de que se complete algo já vivido. Tal estabilidade faz com que ela tenha um olhar para o futuro através de seu processo pessoal.

E ali mesmo, Stein comenta que, até se romperem todas, deve "suportar tranquilamente as correntes que me são impostas": ou seja, viver o limite e o sofrimento que lhe cabe com o olhar da experiência de unidade (experimentada como estável), e acrescenta que não está em nossas mãos romper as correntes: "Não devemos fazer o que é competência dos anjos" (STEIN, 2002a, carta 226, p. 869); o silêncio vivido na unidade estável permite passar pelo sofrimento de modo livre. Viver o sofrimento faz parte do processo da vida; e pode ser embebido na relação de unidade, embebido pelo ideal, embebido pelo acontecimento de amor.

Uma expressão que Stein utiliza e que tem a ver com a experiência própria da sexta morada do castelo interior, o campo da experiência estável: a definitividade da aliança com Deus "reduz a silêncio todas as perguntas" (STEIN, 2002a, carta 450, p. 1134). As inquietações estão lá, o não saber continua, a preocupação com o que vai acontecer permanece, mas a estabilidade da união "reduz a silêncio todas as perguntas".

Stein apresenta a sexta morada do castelo interior como campo da total confiança do soldado vitorioso durante a batalha perigosa (STEIN, 1999a). Não se trata de ausência de batalha, nem de batalha sem perigo, mas sobretudo de confiança enquanto se batalha, claro efeito da estabilidade da união entre a pessoa e o mistério vivo.

Em outra carta Stein comenta com uma pessoa doente que mais tarde "tomará o silêncio e a solidão com muita gratidão" e se questiona sobre a ligação entre o momento de sofrimento presente e o percurso de vida daquela pessoa: "E quem sabe para quê você agora terá de reunir as forças" (STEIN, 2002a, carta 518, p. 1225).

Em meio a dor e limite, a batalha marcada pela confiança vivida no silêncio. Em termos de eu, é como se a pessoa o definisse não pelos elementos da própria história, mas pelo acontecimento da própria 
história; não pela descrição dos limites ou das possibilidades, mas do que de grandioso/misterioso acontece na própria história.

A figura de João é exemplar nesse sentido, segundo o que ele nos deixou registrado no Evangelho redigido por ele: ali, ao invés de falar "eu" diz "aquele que Jesus amava": voltar-se àquele acontecimento é a maneira mais clara, mais livre, mais límpida de falar "eu". E é estável, porque não depende se vai bem ou mal, se algo dá certo ou não: "aquele que Jesus amava" (Cf. Jo 13,23; 19,26; 20,2; 21,7.20).

\section{Silêncio e o centro da alma}

Na sétima e última morada do castelo interior, os sentidos e as potências da alma (intelecto, memória e vontade) não mais servem de meios para reconhecimento e união com o mistério, mas o fluxo que se comunica à alma flui desde seu íntimo também sobre aquelas potências (STEIN, 1999a). E "a alma não se move de seu centro e não perde a sua paz" (p. 138) nos momentos de contemplação ou de atividade: amor contemplativo e operante, atenta ao amado em todo gesto; sem buscar alegrias, vive "terna gratidão" (p. 139). As solicitações divinas advêm do centro da própria alma, lugar da íntima e radical união.

E todo conhecimento agora se dá de modo "tranquilo e silencioso" (STEIN, 1999a, p. 139), sem necessidade de qualquer esforço do intelecto.

\section{Considerações finais}

Ao final de seu texto "O castelo interior", Stein (1999a), tendo percorrido as etapas de todas as sete moradas, reafirma que examinara a experiência mística assim como descrita por Teresa D’ Ávila (2008) em termos de antropologia filosófica, pois se refere à experiência propriamente humana.

A alma tem conhecimento não só do mundo externo mas também de si mesma: é cônscia de toda a sua vida espiritual e pode refletir sobre si mesma sem chegar a ela pela porta da oração. Por outro lado, é preciso 
também considerar frente a qual $\mathrm{Si}$ a alma vem a se encontrar e isso depende de de qual outra porta ela entra em si (STEIN, 1999a, p. 141, itálico da autora).

E aponta como possíveis "portas" para a reflexão sobre si e para adentrar a própria interioridade os relacionamentos com outros seres humanos, a necessidade de conhecer-se (ainda que possa ser fonte de ilusões ou de ocultamento da própria essência) e a pesquisa científica sobre o mundo interior (STEIN, 1999a).

Quanto a esta última "porta" referida, Stein chega a indicar algumas possíveis consequências para sua abordagem científica da experiência propriamente humana, contemplando a interioridade pessoal. Acentuando que o eu aparece como esse ponto móvel, depositando-se em diversos âmbitos da experiência, adentrando ou não a interioridade, respondendo livremente a apelos pode dar-se a luz da consciência. Um ponto central do eu, ao viver o movimento, ilumina a si mesmo, além de iluminar o próprio caminho, o mundo-da-vida e o mistério do mundo.

A pessoa voltada para a exterioridade, distraída no âmbito dos objetos, inclusive tomando a si mesma como objeto, como chega a ter a possibilidade de um movimento desse? A resposta se dá pelo "apelo" advertido e também pelo "impulso" que constitui o eu, impulso pelo qual aquele centro do eu vive, impulso que é o núcleo pessoal.

Diante de um apelo, podemos evitá-lo ou aderir a ele; de qualquer modo já houve um reconhecimento de algo significativo. Temos um impulso para esse reconhecimento, um impulso para ir adiante na experiência que se apresenta.

Assim, ao ver uma pessoa se ajoelhando, vivo um impulso de olhar para onde ela está olhando, impulso para ir além do empírico e colher a vivência e o significado a se oferecer ali. Há um impulso pelo sentido, ainda que possa ser banalizado, ainda que possa forjar um sentido arbitrariamente, ou possa enraivecer-me pelo fato de que as coisas e seu sentido não dependem apenas de mim... Posso me movimentar de diversas maneiras, mas o primeiro impulso é de reconhecimento e de sentido tanto dos objetos quanto de si mesmo. 
Outro aspecto importante em que a mística ilumina a experiência propriamente humana se refere à autoconsciência e descrição da interioridade pessoal, e Stein aponta Teresa D' Ávila e Agostinho como mestres naquela arte:

Mestres da autoconsciência e da autodescrição, eles iluminaram as misteriosas profundidades da alma: não iluminaram somente os "fenômenos". A superfície agitada da vida da alma são, para eles, fatos inegáveis da experiência, mas também as forças, que pulsam na imediata vida consciente da alma e enfim até a essência da alma (STEIN, 1999a, p. 145).

Significativa a crítica à ciência descritiva (particularmente a psicologia) por definir como seu objeto apenas a superficialidade. E vai adiante apontando que a descrição contém um convite a adentrar a experiência em outros níveis. Então o desafio lançado é não ficar na superfície agitada da experiência humana mas colher o pulsar da vida consciente e nesse reconhecimento da vida pulsando em si há reconhecimento de si mesmo e do acontecimento da vida e seu mistério contemporaneamente, em união; e essa experiência ativa a movimentação do eu assim como ativa memória, intelecto e vontade (as "potências da alma"). O exercício da fenomenologia é um chamado ao exercer dessa grandeza.

E quanto ao que seria ir além do nível da experiência meramente empírica:

Sendo a alma uma realidade espiritual pessoal, o seu íntimo, a sua particularidade intrínseca, em suma a essência da qual afloram as suas forças e a interação da sua vida não são apenas algo desconhecido, que admitimos como dado para explicar os fatos espirituais experienciáveis, mas são também algo que pode se tornar claro, tangível, ainda que permanecendo misterioso (STEIN, 1999a, p. 145-146).

Não se trata de montar um constructo de algo que esteja por trás para explicar o processo; trata-se de acessar o processo acontecendo, reconhecer elementos tangíveis ainda que misteriosos.

Posso, por exemplo, não saber dizer exatamente por que sua presença me provoca além do impacto da imagem visual, mas posso 
descrever com clareza que essa é uma provocação de sua presença para mim. Posso não saber dizer qual é a fonte da vida, mas que a vida tem uma fonte, que meu eu faz parte da vida fluindo e acontecendo é algo tangível, tangível com os olhos da inteligência, é experiência.

Então, o problema do recolhimento do eu e do silêncio não se refere a se retirar do mundo sossegadamente, mas refere-se ao campo da liberdade, ao campo da ação, da pessoalidade, onde o mundo já não é estranho, onde eu já não sou estranho a mim mesmo, onde se pode estar em casa consigo mesmo.

Recolher-se como silêncio vivido tem força criativa de humanidade.

E para encerrar o presente texto com a abertura de experiência e consciência do mistério que caracteriza Edith Stein, uma frase de uma carta dela (STEIN, 2002a, carta 325, p. 979), aqui dirigida a todo leitor: "Creio que esse silêncio interior seja o que de melhor eu possa desejar a você. Você tem muitas perguntas guardadas em seu coração que eu não posso responder".

\section{Referências}

ALES BELLO, A. Edith Stein o dell'armonia: esistenza, pensiero, fede. Roma: Studium, 2009.

ALLERS, R. On darkness, silence and the nought. The thomist: a specutlative quarterly review, Washington, v. 9, n. 4, p. 515-572, out. 1946.

FACULDADE DEHONIANA. Teologia em Questão. O pensamento de Edith Stein: escritos críticos, Taubaté, v. 15, n. 2, 2016.

KUSANO, M. B. A Antropologia de Edith Stein: entre Deus e a Filosofia. São Paulo: Ideias \& Letras, 2014.

MACINTYRE, A. C. Edith Stein: a philosophical prologue, 1913-1922. Lanham: Rowan \& Littlefield, 2006. 
MAHFOUD, M. Formação da pessoa e caminho humano: Edith Stein e Martin Buber. In: MAHFOUD, M.; MASSIMI, M. (Org.). Edith Stein e a psicologia: teoria e pesquisa. Belo Horizonte: Artesã, 2013. p. 153-165.

MAHFOUD, M. Morro Vermelho: fé, memória e história. In: BOSCHI, C. C.; PINHEIRO, L. A. (Org.). A Arquidiocese de Belo Horizonte e a Evangelização. Belo Horizonte: PUC Minas, 2014. p. 399-412.

MAHFOUD, M.; SAVIAN FILHO, J. (Org.). Diálogos com Edith Stein: Filosofia, Psicologia, Educação. São Paulo: Paulus, 2017.

MASSIMI, M. Compreender a estrutura da pessoa: diálogo entre fenomenologia e filosofia aristotélico-tomista, por Edith Stein. In: MAHFOUD, M.; MASSIMI, M. (Org.). Edith Stein e a psicologia: teoria e pesquisa. Belo Horizonte: Artesã, 2013. p. 101-126.

PARREIRA, W. A. Fenomenologia e espiritualidade: consciência e meditação. Memorandum, Belo Horizonte, n. 27, p. 61-72, 2014. Disponível em: <http://seer. ufmg.br/index.php/memorandum/article/view/6371>. Acesso em: 8 set. 2017.

PETERSEN, M. T. K. A hermeneutics of contemplative silence: Paul Ricoeur and the heart of meaning. PhD (Doctor of Philosophy) thesis - University of Iowa, 2011. Disponível em: <http://ir.uiowa.edu/cgi/viewcontent. cgi? article $=5501 \&$ context $=$ etd $>$. Acesso em: 8 set. 2017 .

SANTOS, G. L.; FARIAS, M. R. (Org.). Edith Stein: a pessoa na filosofia e nas ciências humanas. São Paulo: Fonte, 2014.

SAVIAN FILHO, J. (Org.). Empatia: Edmund Husserl e Edith Stein: apresentações didáticas. São Paulo: Loyola, 2014.

SBERGA, A. A. A formação da pessoa em Edith Stein: um percurso de conhecimento do núcleo interior. São Paulo: Paulus, 2015.

STEIN, E. Il castello interiore. In: STEIN, E. Natura, persona, mistica: per una ricerca cristiana della verità. 2. ed. Trad. Barbara Venturi. Roma: Città Nuova, 1999a. p. 115-147. 
STEIN, E. La struttura ontica della persona e la problematica della sua conoscenza. In: STEIN, E. Natura, persona, mistica: per una ricerca cristiana della verità. 2. ed. Trad. Barbara Venturi. Roma: Città Nuova, 1999b. p. 49-113.

STEIN, E. Sull'idea di formazione. In: STEIN, E. La vita come totalità: scritti sull'educazione religiosa. 2. ed. Trad. Teresa Franzosi. Roma: Città Nuova, 1999c. p. 21-36.

STEIN, E. Cartas. In: STEIN, E. Obras completas: vol. I: Escritos autobiográficos y cartas. Trad. Jesús García Rojo et alii. Vitoria: El Carmen, 2002a. p. 551-1413.

STEIN, E. Como llegué al carmelo de Colonia. In: STEIN, E. Obras completas: vol. I: Escritos autobiográficos y cartas. Trad. Jesús García Rojo et alii. Vitoria: El Carmen, 2002b. p. 497-510.

STEIN, E. Vida de una família judia. In: STEIN, E. Obras completas: vol. I: Escritos autobiográficos y cartas. Trad. Jesús García Rojo et alii. Vitoria: El Carmen, 2002c. p. 158-491.

STEIN, E. Caminos del conocimiento de Dios: la "teología simbólica" del Areopagita y sus presupuestos objetivos. In: STEIN, E. Obras completas: vol. V: Escritos espirituais. Trad. Francisca Javier Sancho et alii. Madrid: Editorial Espiritualidad, 2004. p. 123-181.

STEIN, E. Los caminos del silencio interior. In: STEIN, E. Los caminos del silencio interior. 5. ed. Trad. Andrés Bejas e Sabine Spitzlei. Buenos Aires: Bonum, 2007. p. 89-92.

STEIN, E. La struttura della persona umana: corso di antropologia filosofica. Trad. Michele D'Ambra. Roma: Città Nuova, 2013.

TERESA D’ÁVILA. Castelo interior ou moradas. 14. ed. Trad. Carmelitas Descalças do Convento de Santa Teresa do Rio de Janeiro. São Paulo: Paulus, 2008.

Recebido: 04/10/2017

Received: 10/04/2017

Aprovado: 10/11/2017 Approved: 11/10/2017 